\title{
Implications of Groundwater Depletion for Aquifer Geomatrix Deformation and Water Availability
}

\author{
Juana P. Moiwo, ${ }^{1,}$, Yahaya K. Kawa ${ }^{2}$, John P. Kaisam², Umu Lamboi ${ }^{3}$ \\ ${ }^{1}$ Department of Agricultural Engineering, School of Technology, Njala University, Njala Campus, Sierra Leone \\ ${ }^{2}$ Department of Chemistry, School of Environmental Sciences, Njala University, Njala Campus, Freetown, Sierra Leone \\ ${ }^{3}$ Department of Physics and Computer Science, School of Technology, Njala University, Njala Campus, Sierra Leone
}

\section{Email address:}

jupamo2001@yahoo.com (J. P. Moiwo)

${ }^{*}$ Corresponding author

\section{To cite this article:}

Juana P. Moiwo, Yahaya K. Kawa, John P. Kaisam, Umu Lamboi. Implications of Groundwater Depletion for Aquifer Geomatrix Deformation and Water Availability. Hydrology. Vol. 4, No. 5, 2016, pp. 46-57. doi: 10.11648/j.hyd.20160405.11

Received: September 2, 2016; Accepted: October 14, 2016; Published: December 12, 2016

\begin{abstract}
Worsening water storage depletion contributes to environmental degradation, land subsidence and earthquake or even disrupts food production/security and social stability. There is also the need for efficient water use strategies in populated regions, especially when such regions also have intensive agricultural and industrial activities. The North China Plain (NCP) is one such region which is not only the seat of power, but also a major agricultural and industrial with a severe water storage depletion. Thus this study integrates satellite, model and field data products to investigate water storage depletion and land subsidence in the Beijing Environs of NCP. In the first step, GRACE (Gravity Recovery and Climate Experiment) mass rates are analyzed for water storage depletion in the region. Next, GRACE total water storage (TWS) is corrected for soil moisture storage (SMS) to derive groundwater storage (GWS) using GLDAS (Global Land Data Assimilation System) data products. The derived GWS is compared with GWS obtained from field-measured groundwater level to show water storage depletion in the study area. Then GPS (Global Positioning System) data of relative land surface change are used to show land subsidence due to water storage depletion. A total of $\sim 96$ near-consecutive months (Jan. 2002 through Dec. 2009) of datasets are used in the study. Based on GRACE mass rates, TWS depletion is $36.54 \pm 1.74 \mathrm{~mm} \mathrm{yr}^{-1}$ or $6.34 \pm 0.29 \mathrm{~km}^{3} \mathrm{yr}^{-1}$ for the $169000 \mathrm{~km}^{2}$ study area. Analysis of relative land surface change shows the occurrence of land subsidence at $7.29 \pm 0.35{\mathrm{~mm} \mathrm{yr}^{-1}}^{1}$ in the Beijing Environ of NCP. About $7.50 \%\left(2.74 \pm 0.18 \mathrm{~mm} \mathrm{yr}^{-1}\right.$ or $\left.0.46 \pm 0.03 \mathrm{~km}^{3} \mathrm{yr}^{-1}\right)$ of the depletion in TWS and $5.25 \%$ $\left(1.52 \pm 0.07 \mathrm{~mm} \mathrm{yr}^{-1}\right.$ or $\left.0.26 \pm 0.01 \mathrm{~km}^{3} \mathrm{yr}^{-1}\right)$ of that in GWS are attributed to storage reductions due to the land subsidence. Storage loss in the region justifies the current south-north water transfer efforts in the region. The concurrence of water storage depletion and land subsidence could have adverse implications for the hydrology, ecology, food security and social stability of the region. It is important to devise efficient measures to avert the negative effects of water storage depletion in the study area.
\end{abstract}

Keywords: Beijing Environs, Water Storage Depletion, Land Subsidence, Hydrogeodetic Data

\section{Introduction}

Groundwater is a vital source of water supply for humans, agriculture, industries and high-value ecosystems [1, 2]. Current global groundwater withdrawal is estimated at $750-800 \mathrm{~km}^{3} \mathrm{yr}^{-1}$ [3], providing some $50 \%$ of drinking water needs, $40 \%$ of industrial water demand and $20 \%$ of irrigation water supply [4]. Along with the benefits (e.g., increased food production and socio-economic growth) are also the consequences (e.g., storage depletion, quality deterioration, ecological degradation, land subsidence, seawater intrusion and water conflicts) of groundwater exploitation [1, 5]. Excessive groundwater exploitation over long periods could induce land subsidence [6-8] or even earthquake [8, 9].

Groundwater withdrawal reduces pore pressure and also concurrently increases effective stress; a condition that causes aquifer compaction, land subsidence or earthquake [9-11]. Subsidence is the elastic/inelastic compaction of crustal materials due to changes in stress dynamics [12, 13]. Subsidence due to groundwater unloading is the compaction 
of clay-silt/sand-gravel deposits [1, 14]. Aquifer recharge restores lost pore-water pressure that in turn induces elastic rebound of aquifer materials [14].

Despite its significance or even because of it, current global rates of groundwater development are unsustainable $[1,14,16]$. Under certain conditions, physical changes within aquifer/crustal systems due to storage loss can be permanent, leading to unrecoverable loss of storativity. Groundwatercontrolled crustal deformations like groundwater depression cones and land subsidence have been reported in Arizona/Texas [6], Mexico City [17], Jakarta [18], Ravenna [19], Taiwan [20] and Lorca/Spain [9]. Other crustal deformations and the related effects are detailed by González et al. [9] for the Los Angeles Basin in USA and by Rodolfo and Siringan [21] for East Asia. Poland et al. [22] detected a record groundwater-controlled subsidence of $>8.5 \mathrm{~m}$ in San Joaquin Valley of California. There are several such reports on land subsidence due to long-term groundwater withdrawals in China and elsewhere across the globe [11, 24-25].

Monitoring land surface change (LSC) for crustal deformation is the critical first step towards developing effective subsidence intervention measures $[12,26]$. Several techniques exist for LSC monitoring, including spirit leveling, piezometric/reservoir pressure measurement, geodimeter measurement and extensometer measurement. Also radioactive marker techniques, modeling techniques and space-borne techniques like GPS (Global Positioning System) and InSAR (Interferometry Synthetic Aperture Radar) are now available. The procedural details of several LSC monitoring techniques are discussed by $[8,10,18,23$, 27]. Here, GPS data product of relative LSC is used in combination with hydrological data products from GRACE (Gravity Recovery and Climate Experiment), GLDAS (Global Land Data Assimilation System) and field-observed groundwater level and soil moisture storage (SMS) to characterize water storage depletion and land subsidence in the Beijing Environs of North China Plain (NCP).

GRACE is a twin-satellite system launched in March 2002 to monitor the dynamics in global water storage [28]. The twin satellites orbit the Earth in tandem at a separation distance of $\sim 200 \mathrm{~km}$ and initial altitude of $\sim 450 \mathrm{~km}[29,30]$. Changes in the separation distance between the twin satellites due to variations in gravity pull are measured by an onboard $\mathrm{K}$-band microwave to the nearest nanometer. At any given point in time, the orbit positions of the twin satellites are tracked by GPS receivers and related with the inter-satellite distance driven by gravity fields [31, 32]. Then mass redistributions within the Earth (e.g., due to atmospheric surface pressure, ocean bottom pressure, and changes in storage of terrestrial water and snow/ice) are inferred from the time-variable gravity fields $[30,33]$. After removing nonhydrologic effects, the GRACE gravity field residuals are closely related with terrestrial water storage changes derived from field measurements or model estimates at spatial scales $\geq 160000 \mathrm{~km}^{2}$ [34-41].

GLDAS uses land surface models (e.g., Mosaic, Noah,
Community Land Model, Variable Infiltration Capacity and Catchment Model) to estimate global land surface energy states, including soil moisture, runoff and potential evapotranspiration (ET) $[38,39]$. Due to the high complementarity of the data types in terms of spatial/temporal coverage and accuracy, GRACE and GLDAS data products are integratively used to analyze terrestrial water storage dynamics and to develop sustainable management measures [30, 37, 40].

In this study, GRACE total water storage (TWS) is corrected for groundwater storage (GWS) using GLDASderived SMS and then compared with GWS from fieldmeasurements to show water storage depletion and land subsidence in the Beijing Environs of NCP. Next, the storage-unloading subsidence is verified by GPS data products of relative LSC in the region. The study depicts a novel demonstration of the application of GRACE/GLDAS data products in crustal deformation analysis, going beyond the conventional water storage analysis for such data products. Thus the study not only deepens our current understandings of the implications of storage depletion, but also strengthens the need for developing sustainable water resources use strategies. This is significant not only for research, planning and policy judgement, but also for food production and social stability in the region and beyond.

\section{Materials and Method}

\subsection{Study Area}

The study area, the Beijing Environs of NCP, lies between longitudes $113.8-119.8{ }^{\circ} \mathrm{E}$ and latitudes $37.5-42.6{ }^{\circ} \mathrm{N}$ and covers an area of $\sim 169000 \mathrm{~km}^{2}$ (Fig. 1, top plate). With a population of over 112 million, NCP accounts for over $45 \%$ of China's grain production and $15 \%$ of its gross domestic product $[2,5,41,42]$.

Potential ET $\left(985 \mathrm{~mm} \mathrm{yr}^{-1}\right)$ in cultivated lands is about two times the average annual precipitation $\left(500 \mathrm{~mm} \mathrm{yr}^{-1}\right)$, which is sustained by intensive irrigation [15, 37]. The thick Quaternary alluvial deposits $(>1000 \mathrm{~m})$ are a little poorly drained with average hydraulic conductivity of $>100 \mathrm{~m} \mathrm{~d}^{-1}$ $[2,20,47]$. Because of intensive water use (especially in agriculture and industry), water exploitation in the region far exceeds precipitation recharge [2, 45]. There is sustained surface water depletion and water table head loss (of about 1-2 $\mathrm{m} \mathrm{yr}^{-1}$ ) driven by the ever-widening gap between water use and recharge $[15,20]$. The pumping rates (due to groundwater irrigation) are neither balanced by increased recharge nor decreased discharge, worsening water shortage in the region $[2,15]$.

Depression cones of $40-50 \mathrm{~m}$ and $60-80 \mathrm{~m}$ have developed respectively in the shallow and deep aquifer systems, raising concern for storage depletion effects beyond water shortage for it various uses [7, 25]. While groundwater recovery is cited in recent years [46], there is no confirmed report of decreasing water use or increasing precipitation/recharge in the region $[2,15]$. The difficulties in 
the water budget accounting deepens the uncertainties in the storage dynamics, hence the need for efficient and

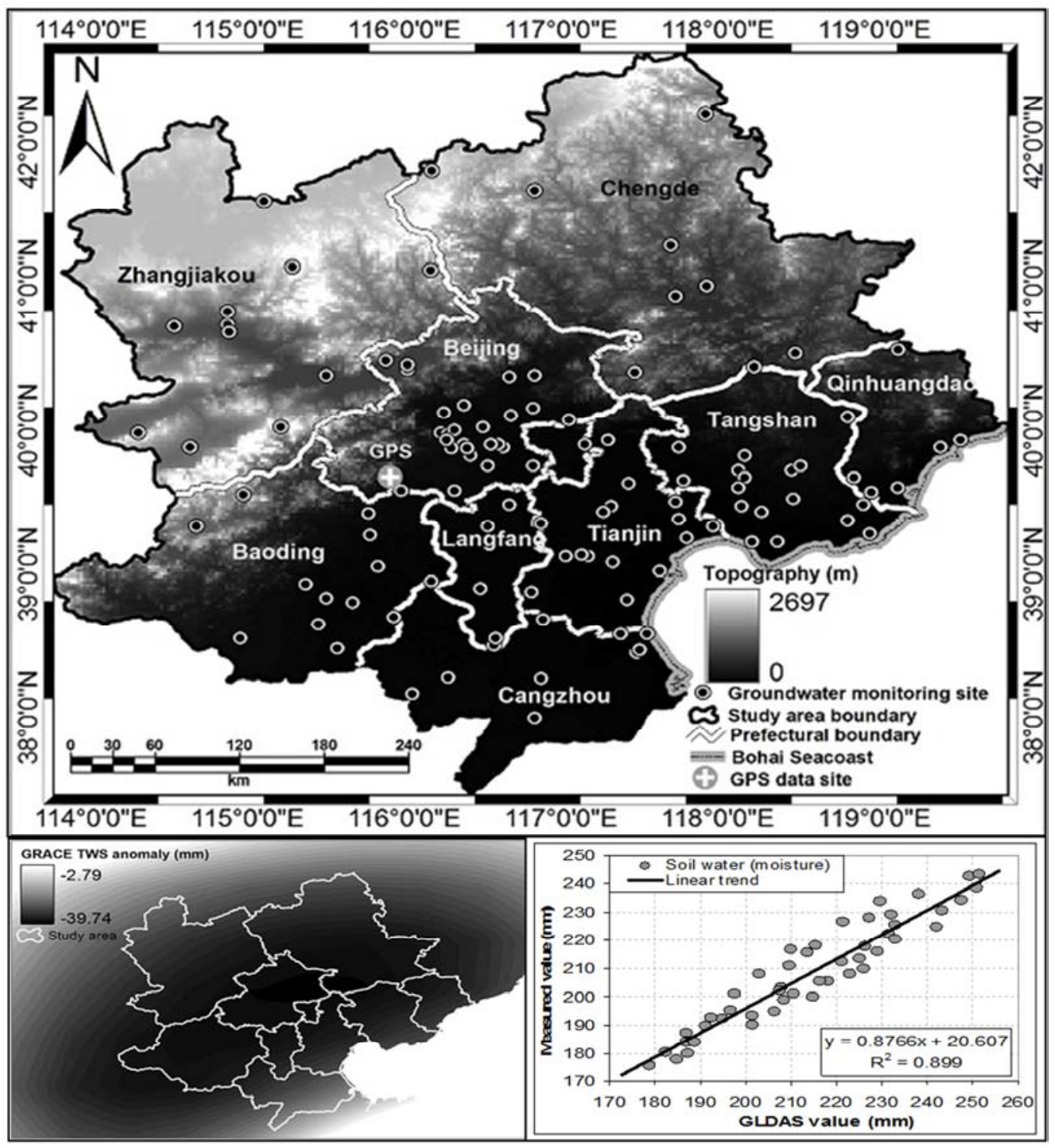

Figure 1. Map of the Beijing Environ of North China Plain depicting groundwater monitoring well sites, GPS relative land surface data site, prefectural boundaries and ambient topography (top plate); GRACE-averaged monthly total water storage anomaly as linear trend for the observation period (bottom left plot); and a plot of field-measured versus GLDAS soil moisture storage (bottom right plot) for the study area.

\subsection{Basic Concept}

Pumping wells generate stress disturbances that propagate through aquifer systems and cause pressure/head loss at magnitudes dependent on the hydrogeologic conditions. Stress change due to pumping could result in the compaction of hydrogeologic formations and land subsidence [13]. Subsidence, which is the response of compressible hydrogeologic formation to changes in fluid pressure within the formation, is quantified in terms of effective stress as $[6$, 47, 48]:

$$
\sigma_{e}=\sigma_{T}-p_{w}
$$

where $\sigma_{T}$ is total stress (ML-1T-2), $\sigma_{e}$ is effective stress (ML-1T-2), and $p_{w}$ is pore-water pressure (ML-1T-2).
The three common compaction stresses are gravitational stress, hydrostatic stress and dynamic seepage stress [23]. While hydrostatic stress is largely neutral, gravitational stress and dynamic seepage stress are additive in effect and together change the void ratio and mechanical properties of aquifer deposits. The combined effect, known as geostatic pressure or total stress $\left(\sigma_{T} ;\right.$ ML-1T-2), of sediments and water at a reference plane below the water table is the unit weight $\left(\gamma_{m}\right.$; ML-2T-2) times the thickness $\left(z_{1} ; \mathrm{L}\right)$ of moist sediments above the water table plus the unit weight $\left(\gamma_{b} ;\right.$ ML-2T-2) times the thickness $\left(z_{2} ; \mathrm{L}\right)$ of buoyant saturated sediments below the water table $[47,48]$ :

$$
\sigma_{T}=z_{1} \gamma_{m}+z_{2} \gamma_{b}
$$


where $\gamma_{m}=\left[g(1-n)+r_{s}\right] \gamma_{w}$ and $\gamma_{b}=[g(1-n)+n] \gamma_{w} ;$ in which $g$ is average specific gravity of the grain deposits (-), $r_{s}$ is average specific retention of the moist grains (-), $n$ is average porosity of the aquifer deposits (-), and $\gamma_{w}$ is specific weight of water (ML-2T-2). Details on the links between subsidence and elastic/inelastic storage coefficients (e.g., specific storage/yield, aquifer thickness, etc.) and other aquifer properties (e.g., pore-water pressure, hydraulic conductivity, etc.) are documented by Poland [47] and Galloway et al. [12].

The degree 2, order 0 (C20) of GRACE spherical harmonic (SH) coefficients can be estimated from satellite laser ranging [28]. Then the other GRACE SH coefficients approximated to degree and order 60 for variations in surface mass density $\left(\Delta S_{0}\right)$ in an area $\left(R_{0}\right)$ are calculated as [5]:

$$
\Delta S_{0}=\frac{4 \pi a^{3} \rho \mathrm{E}}{3 R_{0}} \sum_{l=0}^{L \max } \sum_{m=0}^{l} \frac{2 l+1}{1+k_{l}^{\prime}}\left(\vartheta_{l m}^{c} \Delta C_{l m}+\vartheta_{l m}^{s} \Delta S_{l m}\right)
$$

where $\Delta S_{0}$ [ML3] is the variation in surface mass density, $R_{0}$ [L2] is the area of interest, $a[\mathrm{~L}]$ and $\rho E$ [ML3] are the mean radius and density of the Earth, $k_{l}^{\prime}$ is the $l^{\text {th }}$ load potential Love number, $\Delta C_{l m}$ and $\Delta S_{l m}$ are the $\mathrm{SH}$ coefficient anomalies with respect to mean gravity field for the period of interest, and $\vartheta_{l m}^{c}$ and $\vartheta_{l m}^{s}$ are the $\mathrm{SH}$ coefficients of the study-area kernel function $h$.

After glacial isostatic adjustment [49], north-south stripe filtering, high-frequency noise smoothing and local kernel averaging [28], the surface mass variations are inverted for TWS anomalies comparable to field-measured or modelestimated values [5]. Then piezometric head measurements are inverted for groundwater storage anomaly via storage coefficients $[5,42]-$ specific yield $\left(S_{y}\right)$ for unconfined aquifer and specific storage $\left(S_{s}\right)$ for confined aquifer [29]. Also as storage (especially in semiarid regions) mainly occurs as groundwater and soil moisture [29, 35, 37], GRACE TWS analyses are largely limited to these storage components.

A number of studies have pointed out to aquifer compaction and land subsidence in NCP due to sustained groundwater overdraft since the 1978 land reforms [7, 50, 51]. The trends in SMS, GWS and TWS can serve as a vital signal for potential land subsidence or uplift in a region, either of which can be verified through LSC analysis. The change in the position of mass along the axis of gravity occurs when compaction or subsidence moves mass towards the center of mass of the Earth, causing change in gravity. However, this effect is small with respect to the mass changes addressed in this study and therefore not considered.

In this study, GRACE TWS is corrected for SMS to derive GWS and then the GRACE-corrected GWS compared with field-measured GWS. While negative trends in the water storage anomalies suggest compaction and subsidence, positive trends on the other hand suggest expansion and uplift of the aquifer systems. To verify LSC due to water storage depletion in the Beijing Environs study area, GPS data products of relative LSC are analyzed in relation to the derived TWS anomaly.

\subsection{Data Acquisition and Processing}

The GRACE, GLDAS and GPS data products are used in combination with field-measured SMS and GWS. Except for GRACE (which dataset spans from Apr. 2002 to Dec. 2009), the datasets cover the period from Jan. 2002 through Dec. 2009. The GRACE release-05 data products from CSR (Center for Space Research), JPL (Jet Propulsion Laboratory) and GFZ (German Research Center for Geosciences) used in this study are available at http://geoid.colorado.edu/grace/dataportal.html.

The concept of GRACE data generation and application in hydrology is today quite well documented. GRACE signal detects water storage dynamics across regions with spatial resolutions of $160000 \mathrm{~km}^{2}$ or more [32], which makes it applicable in the $169000 \mathrm{~km}^{2}$ Beijing Environs study area. Here, GRACE monthly solutions are corrected for glacial isostatic adjustments and other non-hydrological effects, destriped for north-south errors, smoothened at $200 \mathrm{~km}$ Gaussian half-width for high-frequency noise and truncated within $1^{\circ}$ (one degree) of the study area over a local averaging kernel $[5,28,40,49]$. The GRACE-derived hydrological fields are afterwards spatially averaged to create time series of TWS anomaly. A linear trend of the spatially averaged GRCAE-estimated monthly TWS anomalies from the 3 geo-centers for the period 2002-2009 is plotted in the bottom left plate of Fig. 1.

The average of the GLDAS-estimated optimal fields of SMS from the 5 surface energy models is used in this study [32]. The GLDAS data product is verified using fieldmeasured SMS data in the study area. Like GRACE, the GLDAS data field is truncated to within $1^{\circ}$ of the study area and spatially averaged (based on the local averaging kernel) to create time series of SMS anomaly. Long-term GLDAS data products are available at http://gdata1.sci.gsfc.nasa.gov/daacbin/G3/gui.cgi?instance_i $\mathrm{d}=$ GLDAS10_M.

The groundwater data are from 138 fairly distributed monitoring wells in the study area (Fig. 1, top plate). About one-third [46] of the monitoring wells are for groundwater level in the confined aquifer and the rest [92] for the unconfined aquifer. The data, also for the period from Jan. 2002 through Dec. 2009, are the averages of three observations $\left(8^{\text {th }}, 18^{\text {th }}\right.$ and $\left.28^{\text {th }}\right)$ per month. The data are converted into GWS anomaly using storage coefficients. To do this, the monthly groundwater data are interpolated (Inverse Distance Weighted Interpolation) in ArcMap separately for the unconfined and confined aquifers.

For the period 2002-2009, groundwater level range across the study area is $66 \mathrm{~m}$ to $-26 \mathrm{~m}$ for the unconfined aquifer and $14 \mathrm{~m}$ to $-87 \mathrm{~m}$ for the confined aquifer. Storage coefficients of the unconfined ( $S y)$ and confined ( $S s$ ) aquifers are $0.012-0.264$ and $0.5639-1.0668 \times 10^{-3} \mathrm{~mm}^{-1}$, respectively $[5,42]$. The mean $S s$ is $0.07829 \times 10^{-3} \mathrm{~mm}^{-1}$, 
which is $\sim 33 \%(0.235)$ that of $S y$ (see http://water.cgs.gov.cn for details). The GWS anomaly derived from field measurements is the product of the interpolated value and the storage coefficient of the respective aquifer systems. This is then summed up and processed in the same way as described for GRACE and GLDAS data products.

Note that the concept of storage coefficient is a simplified assumption of instantaneous drainage of aquifer systems with dropping pressure heads as it ignores delayed drainage effects. While storage coefficients could vary spatially, the change as a function of depth to groundwater can result in non-linear relationship between in-situ groundwater level and storage. However, these effects are not critical in this study as the analysis focuses on long-term averages.

The (frame IGS08) GPS data product of relative LSC is part of the Global Navigation Satellite System (GNSS) or International GNSS Service (IGS) available at http://www.unavco.org/crosscutting/cc-data.html. The data product is processed in GAMIT/GLOBK for daily, looselyconstrained solutions of long-term surface deformation [9, 52] in the region. GAMIT/GLOBK, developed by Massachusetts Institute of Technology (MIT) and sponsored by National Science Foundation (NSF), is a comprehensive package of programs used for analyzing GPS measurements, primarily to study crustal deformations.

Generally, GRACE signal accuracy increases at higher spatial/temporal resolutions [28], thus the analysis focuses on seasonal and annual cycles. However, both average monthly and seasonal cycles are included to show GRACE limitation at short temporal scale. Here, storage anomaly is the storage variation relative to the mean (seasonal or annual) storage for the period 2002-2009. Average monthly cycle is the temporal average for the 12 months in the year and for the 9 years of 2002-2009, along with the spatial average for the study area. Then seasonal cycle is the season-to-season time series for 2002-2009 spatially averaged over the study area. The average seasonal and the yearly (annual) cycles are respectively defined after the average monthly and seasonal cycles. In the Beijing Environs, the period from December to February is winter, March to May is spring, June to August is summer and September to November is autumn.

\subsection{Uncertainty/Bias}

In this study, uncertainty in the GLDAS-derived SMS is measured as the standard deviation of the five-contributing products [32]. The analysis shows that the 5-contributing model-estimated standard deviation is $2.16 \mathrm{~mm} / \mathrm{month}$, which is $<7 \%$ of the average value. Because that GLDAS generally underestimates SMS (especially for irrigated regions), the above level of accuracy is sufficient for a study of this nature. The SMS data from the 60 monitoring sites are spatially averaged (for Jan. 2002 through Dec. 2009) and plotted against the GLDAS-estimated SMS in Fig. 1 (bottom right plot). The GLDAS-derived SMS agrees well $\left(R^{2}=\right.$ 0.899 ) with the field-observed SMS adjusted for irrigation (Fig. 1, bottom right plot).

The GRACE data processing is based on the one-to-zero (center-to-peripheral) averaging kernel function [28] for the study area, which reduces leakage. Induced bias, leakage and amplitude damping as a result of the SH coefficient truncation, glacier isostatic adjustment, destripping, kernel averaging and Gaussian convolution are corrected to reduce uncertainty and bias [35]. Least squares analysis suggests that random errors in the GRACE monthly data are $<5.32$ $\mathrm{mm}$, which is $<5 \%$ of the average error. A further measure of uncertainty in the GRACE data is based on the standard deviation of the 3-contributing GRACE data products. The estimated standard deviation is $1.64 \mathrm{~mm},<6 \%$ of the average value. Although error bars are not shown on the plots, the depicted linear trends and regression equations on the timeseries plots sufficiently highlight the accuracy of the storage anomalies.

\section{Results and Analyses}

\subsection{Seasonal Cycles}

Time series of the seasonal storage anomalies for GWS, SWS and TWS are plotted in Fig. 2 (also see details in Table 1). The anomaly range (denoted as "Dif" in Table 1) is the difference between the maximum and minimum storage amplitudes. It is smallest for SMS and highest for GWS, suggesting that storage in the study area mainly occurs as GWS [5, 42]. The seasonal amplitudes are similar to the seasonal phases because up-scaling (which is upward averaging) limits outlier effects on trend curves. Based on the trend lines, GWS (Fig. 2, top plot), SMS (Fig. 2, middle plot) and TWS (Fig. 2, bottom plot) decline in the study area. The storage trends are not only seasonally driven, but are also significant at $p<0.05$ and $\alpha=0.05$. The seasonality of the storage dynamics is attributed to the prevailing hydroclimatic and agronomic conditions in the region [37].

Table 1. Details of the GLDAS soil moisture storage (SMS), well-monitored groundwater storage (GWS) and GRACE total water storage (TWS) trends for the Beijing Environ of North China Plain.

\begin{tabular}{lllllll}
\hline \multirow{2}{*}{ Storage variable } & & \multicolumn{6}{c}{ Storage parameter } \\
\cline { 3 - 7 } & & $\begin{array}{l}\text { Min } \\
\mathbf{( m m})\end{array}$ & $\begin{array}{l}\text { Max } \\
(\mathbf{m m})\end{array}$ & $\begin{array}{l}\text { Dif } \\
(\mathbf{m m})\end{array}$ & $\begin{array}{l}\text { Mean } \\
(\mathbf{m m})\end{array}$ & $\begin{array}{l}\text { STD } \\
(\mathbf{m m})\end{array}$ \\
\hline \multirow{3}{*}{ GLDAS-derived } & Season & -30.00 & 66.38 & 96.38 & 2.31 & 27.29 \\
SMS anomaly & Year & -33.24 & 40.39 & 73.63 & 0.00 & 22.72 \\
& Avgmon & -29.80 & 18.93 & 53.10 & 0.56 & 16.36 \\
& Avgseas & -10.95 & 16.80 & 27.75 & 2.31 & 11.57 \\
Groundwater & Season & -96.45 & 78.20 & 174.66 & -14.35 & 43.20 \\
storage (GWS) & Year & -58.12 & 52.95 & 111.07 & -7.83 & 34.79 \\
anomaly & Avgmon & -56.77 & 28.16 & 84.93 & -81.67 & 28.64 \\
& Avgseas & -44.46 & 16.59 & 61.05 & -14.25 & 25.13 \\
& Season & -47.10 & 55.23 & 102.34 & 1.72 & 28.31 \\
GRACE-derived & Year & -34.47 & 35.56 & 70.04 & 0.00 & 21.12 \\
TWS anomaly & & & & & & \\
& Avgmon & -23.06 & 45.79 & 68.85 & 1.41 & 18.73 \\
& Avgseas & -14.97 & 16.91 & 31.87 & 1.72 & 14.70 \\
\hline
\end{tabular}

Note that Min is the minimum amplitude; Max is the maximum amplitude; Dif is the difference between Max and Min amplitudes; STD is the amplitude standard deviation; Avgmon is the average monthly storage anomaly; and Avgseas is the average seasonal storage anomaly. 


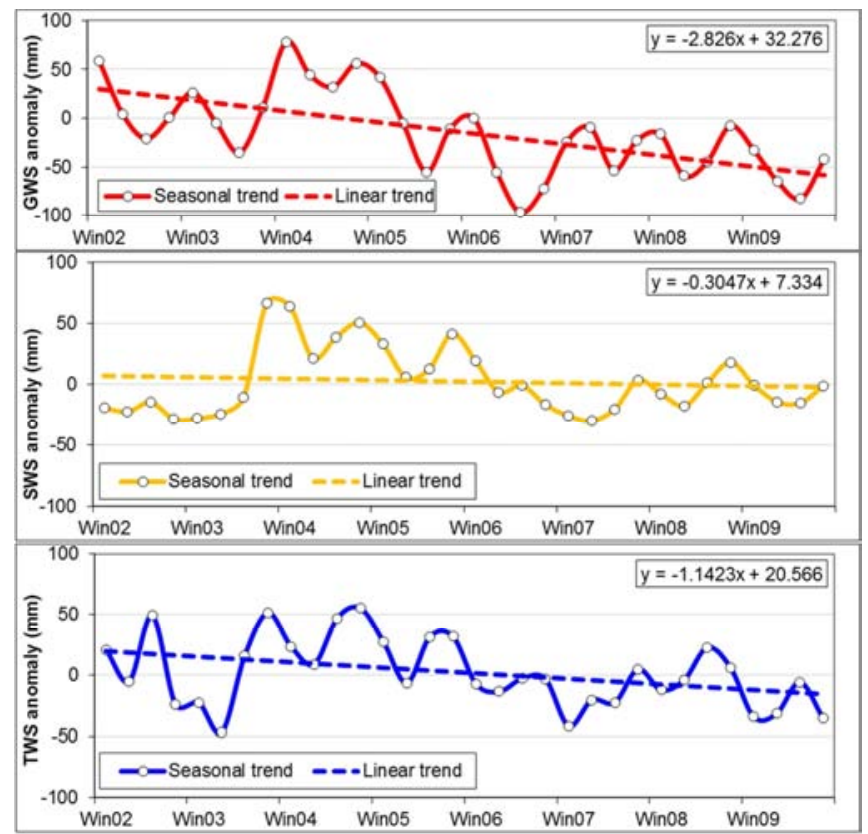

Figure 2. Time series (2002-2009) of seasonal groundwater storage anomaly (top), soil moisture storage anomaly (middle) and GRACE total water storage anomaly (bottom) for the Beijing Environ of North China Plain.

\subsection{Yearly Cycles}

The amplitudes of the yearly storage dynamics in Fig. 3 are much less (due to the up-scale averaging), also with the smallest range for SMS and the highest for GWS. Also the phases of the storage anomalies (Fig. 2; top, middle and bottom plots) are more similar than at the seasonal scale. Like the seasonal cycles, the trends in TWS, SMS and GWS are negative $[5,42]$. The low SMS variability in the study area is attributed to irrigation during non-raining farming seasons. In fact several other studies have noted a generally low SMS anomaly in irrigated farmland regions [32, 37].

The annual storage trends (which are significant at $p<$ 0.01 and $\alpha=0.05$ ) suggest that storage in the region is highest in 2004. Although the trends suggest an apparent recovery in 2006-2008, the overall trend is negative; contradicting recent reports of groundwater recovery in the region [46]. The continuous water storage depletion raises concern for crustal deformation and land subsidence in the study area [53].

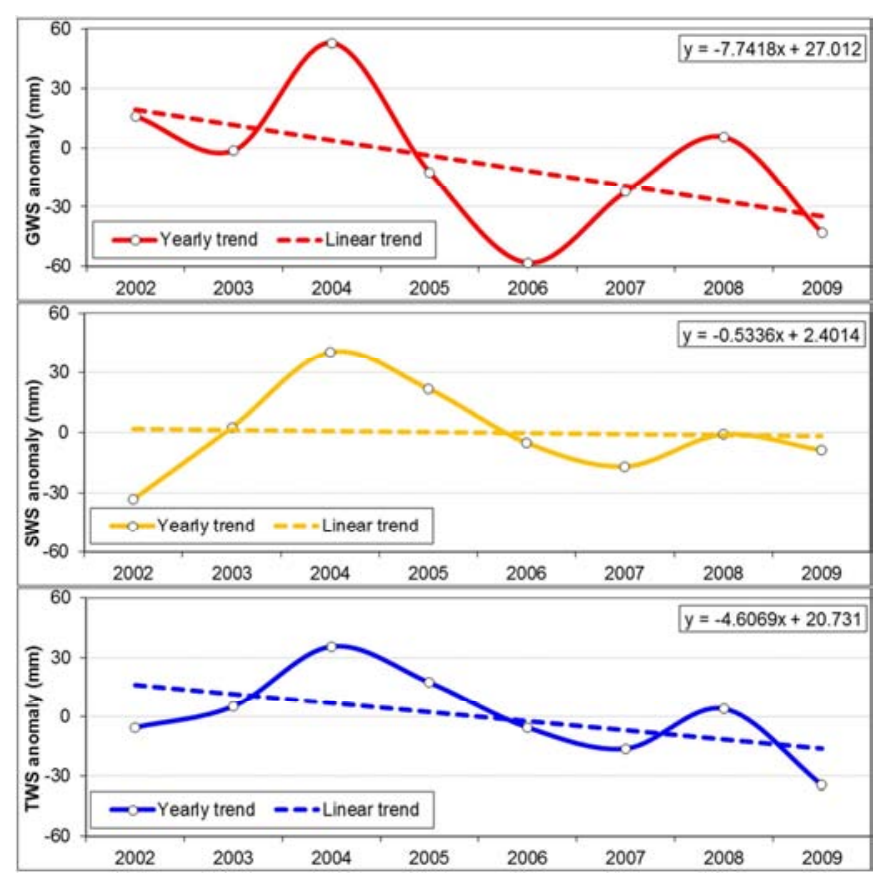

Figure 3. Time series (2002-2009) of yearly groundwater storage anomaly (top), soil moisture storage anomaly (middle) and GRACE total water storage anomaly (bottom) for the Beijing Environ of North China Plain. 


\subsection{Average Monthly Cycles}

Figure 4 depicts the dynamics of the average monthly storage anomalies in the study area. GWS increases from January through February and then decreases through March. It is lowest in June and rebounds through December (Fig. 4, top plot). The storage dynamics is strongly influenced by the rates of precipitation (storage input), irrigation (storage input/output) and ET (storage output) in the study area [2, 20, 42].

The SMS and TWS anomalies differ in amplitude, but similar in phase. The phases generally decline from January through May/June, increase to peak values in August and again decline through December (Fig. 4, top and middle plots). Since GRACE is less sensitive to short-term storage anomalies, TWS anomaly (Fig. 4, bottom plot) is a bit out of phase with measured GWS anomaly (Fig. 4, top plot) in the study area. The above discrepancies could also be due to errors in the GRACE, GLDAS and/or observation data or in the data processing method used.
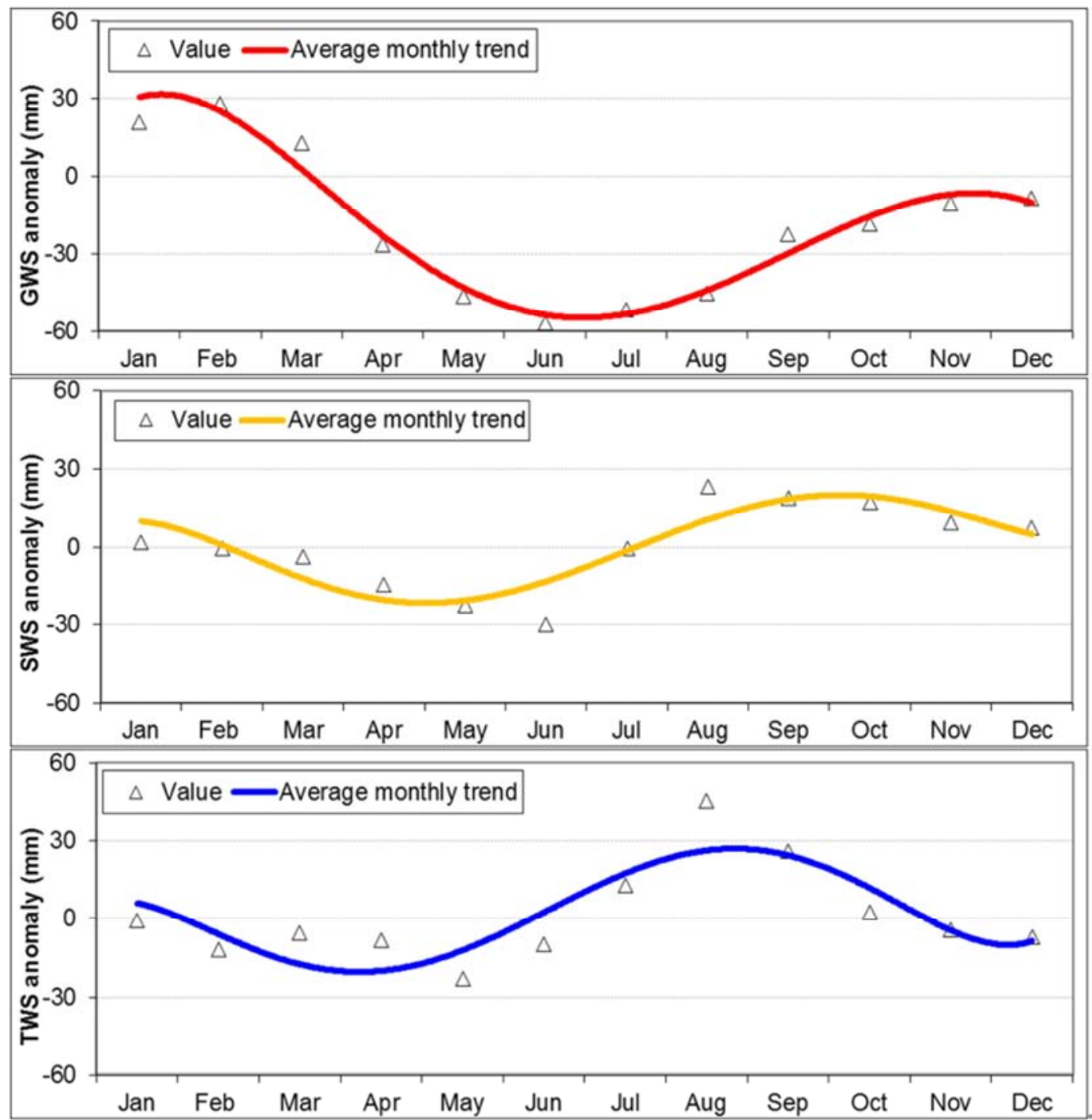

Figure 4. Time series (2002-2009) of average monthly groundwater storage anomaly (top), soil moisture storage anomaly (middle) and GRACE total water storage anomaly (bottom) for the Beijing Environ of North China Plain.

\subsection{Average Seasonal Cycles}

Figure 5 plots the dynamics of the storage anomalies averaged seasonally for the period 2002-2009. Although the GWS and SMS anomalies are similar, both are different from TWS anomaly. This further confirms that GRACE signal is less sensitive to short-term storage variations [28]. The GWS anomaly declines from winter through summer, before rebounding in autumn (Fig. 5, top plot). That of SMS declines from winter to spring and rebounds through autumn (Fig. 5, middle plot).

The trends in the GRACE-derived average seasonal TWS anomaly (Fig. 5, bottom plot) depict horizontal S-shaped (or a breakthrough) curve. It is lowest in spring and highest in summer, which depicts the overall storage characteristics in the region. The storage anomaly depicts the combined effects of water use, precipitation and ET in the study area [2, 15]. 


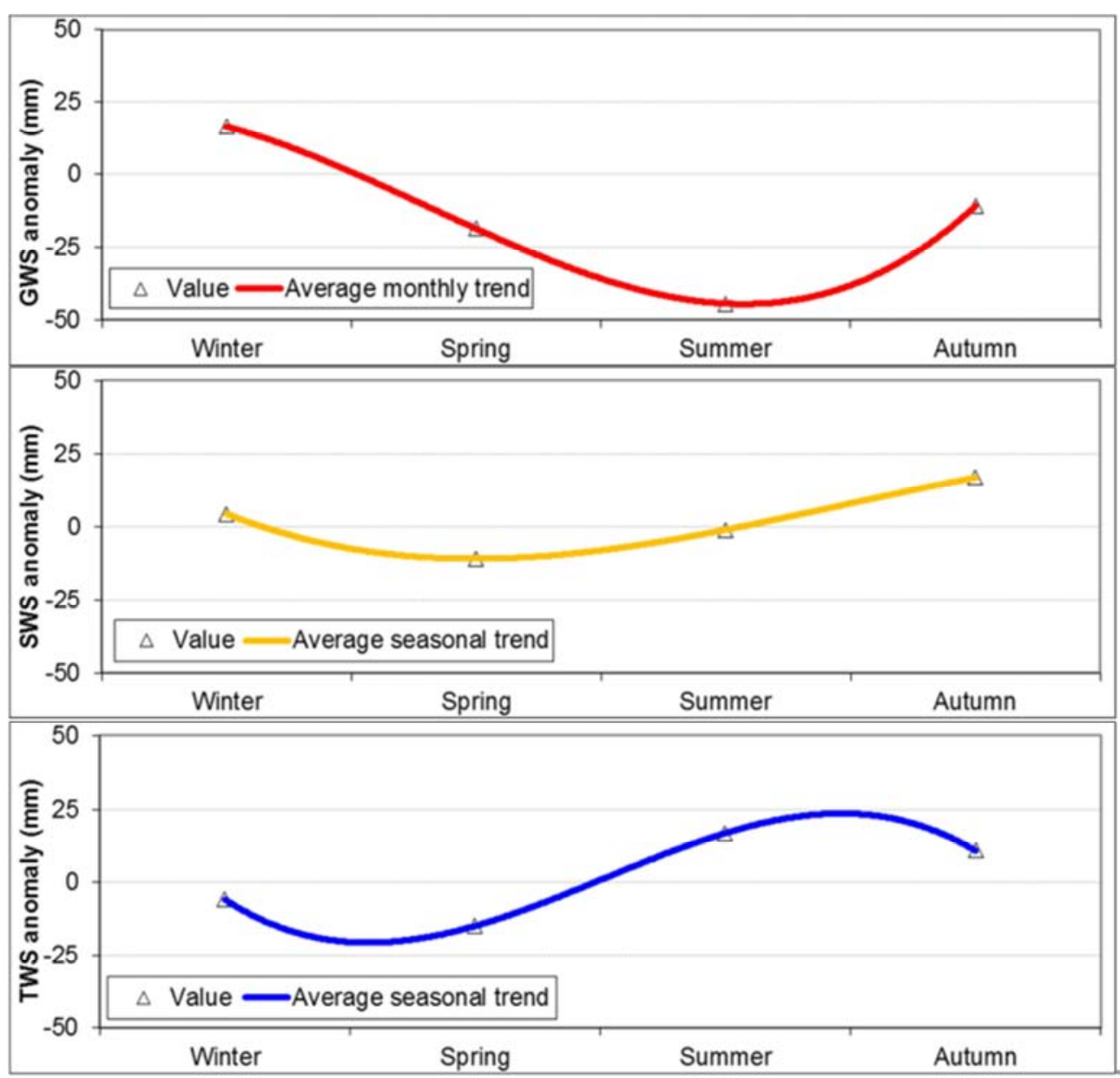

Figure 5. Time series (2002-2009) of average seasonal groundwater storage anomaly (top), soil moisture storage anomaly (middle) and GRACE total water storage anomaly (bottom) for the Beijing Environ of North China Plain.

\subsection{Groundwater Storage Anomaly}

The GWS anomaly derived from observation data is plotted side-by-side that derived from GRACE/GLDAS data products in Fig. 6. The trend in GWS anomaly reflects the rate of groundwater depletion in the study area. The magnitude of the trend (given by the trend-lines and regression equations) in the field-measured GWS anomaly (Fig. 6, top and middle plots on the left) and that in GRACEGLDAS-derived GWS anomaly (Fig. 6, top and middle plots on the right) are negative at both seasonal and annual scales, suggesting an overall storage loss in the study area.

Water budget analysis based on GRACE data shows water storage depletion at the rate of $36.54 \pm 1.74 \mathrm{~mm} \mathrm{yr}^{-1}$, the equivalent of $6.34 \pm 0.29 \mathrm{~km}^{3} \mathrm{yr}^{-1}$ for the $169000 \mathrm{~km}^{2}$ Beijing Environs study area. Also analysis of GLDAS data products shows that $20.75 \%\left(7.58 \pm 0.36 \mathrm{~mm} \mathrm{yr}^{-1} ; 1.28 \pm 0.06 \mathrm{~km}^{3} \mathrm{yr}^{-1}\right)$ of that loss is in SMS. Groundwater and other storage sources account for the remaining $79.25 \%(28.96 \pm 1.38 \mathrm{~mm}$ $\mathrm{yr}^{-1}$ or $4.89 \pm 0.23 \mathrm{~km}^{3} \mathrm{yr}^{-1}$ ) of the storage loss. Feng et al. [5] noted that about $67 \%$ of storage loss in North China is from aquifer storage. The estimated contribution of GWS to TWS loss in the region is $76.84 \%\left(28.28 \pm 1.02 \mathrm{~mm} \mathrm{yr}^{-1}\right.$ or $\left.4.79 \pm 0.23 \mathrm{~km}^{3} \mathrm{yr}^{-1}\right)$. The cumulative storage loss for the 8year period (2002-2009) is $49.40 \pm 2.35 \mathrm{~km}^{3}$ for TWS,
$37.95 \pm 1.81 \mathrm{~km}^{3}$ for GWS and $10.26 \pm 0.49 \mathrm{~km}^{3}$ for SMS. Thus as noted by Strassberg et al. [35] for a semiarid highland in the US, the overall storage dynamics in the study area is little affected $(<3 \%)$ by surface water use.

Sustained water storage depletion over a long period could lead to land subsidence, an event which limits water storage and supply [9]. To determine the occurrence of land subsidence in the Beijing Environs due to water storage depletion, GPS data products of relative LSC are analyzed.

\subsection{Land Subsidence}

Because of the dense population, high agricultural/industrial activities and severe semiarid conditions, water use in NCP exceeds natural recharge $[5,20,55]$. As there are no earthquakes or large faults in the region, land deformation could only be due to the abstraction of groundwater, hydrocarbons or coal [27]. Thus GPS data of relative LSC can be used to determine land subsidence due to water storage loss in the region.

The GPS data analysis suggests the occurrence of subsidence at an estimated rate of $7.29 \pm 0.35 \mathrm{~mm} \mathrm{yr}^{-1}$ (Fig. 6, bottom plot) in the vertical component of the IGS08 station in Beijing (Fig. 1, top plate). Note that Beijing has one of the largest groundwater depression cones in China. Since land 
reforms in the $1970 \mathrm{~s}$, there is sustained subsidence at the rate of $2.97 \mathrm{~mm} \mathrm{yr}^{-1}$ in NCP [50]. The vertical dip of hydraulic gradient from the moderate-to-worst water storage depletion zone in Beijing is $4-30 \%$ [54]. Groundwater accounts for > $61 \%$ of water supply in Beijing, $26 \%$ in Tianjin, $80 \%$ in Hebei province and 58\% in Shanxi province [2], all of which form the NCP.

The magnitude of subsidence is loosely related to the degree of groundwater depletion [9], which is severe for the Beijing Environs,, including Tianjin and the contiguous prefectures (Fig. 1, top plate). For the spatial averaging, it is assumed that the hydro-geologic conditions are uniform across the Beijing Environs study area. This makes the above estimate conservative since it ignores the complex processes of land subsidence. Irrespectively, the analysis lays the basis for future applications of GRACE/GLDAS data products in the study of not only water storage loss, but also other related processes such as subsidence and earthquakes.

There is the possibility of skeletal matrix rearrangement under increased effective stress exceeding pre-consolidation stress in fine grain deposits, resulting in reduced porosity that is permanent and non-recoverable. Skeletal matrix generally compresses under decreased effective stress (not exceeding pre-consolidation stress), also resulting in reduced porosity. However, this deformation is recoverable under stresses in the elastic range. Crushing of granular components of the matrix is possible in sand and especially diatomaceous deposits, but this is rare and tends to occur under very large increases in effective stress [48]. The high storage depletion $[2,54]$ in NCP could result in the above subsidence conditions.
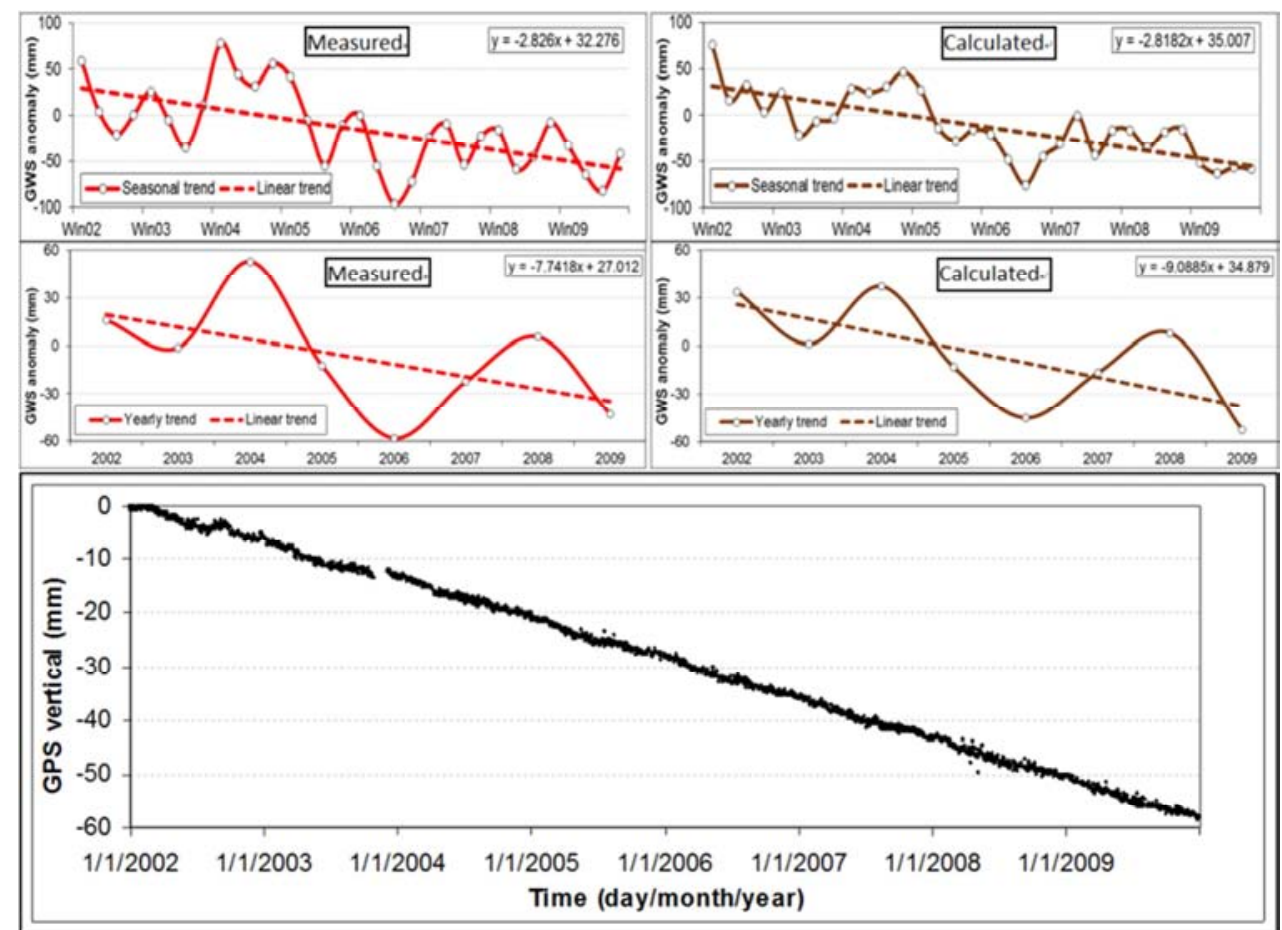

Figure 6. Parallel plots of seasonal (top) and yearly (middle) groundwater storage anomalies separately derived from field-measured groundwater-level data (red) and GRACE-GLDAS hydrology data (brown) products for the Beijing Environ of North China Plain. The bottom plot depicts the vertical component of relative land surface change derived from the GPS data station IGS08 (in Beijing) for the period from January 2002 through December 2009.

\section{Discussions}

Groundwater accounts for some $80 \%$ of irrigation $[15,20]$ and $20 \%$ of industrial and domestic [5] water use in North China. The year-on-year groundwater level decline (1-2 m) suggests that withdrawal exceeds recharge in the region [2]. The over reliance on groundwater is also reflected in the widespread water storage depletion in the region [54, 55, 57].

Based on GPS data analysis, subsidence due to water storage depletion is $7.29 \pm 0.35 \mathrm{~mm} \mathrm{yr}^{-1}$ in the Beijing Environs of NCP. Assuming that the subsidence is all drainable water, it is the equivalent of $1.23 \pm 0.06 \mathrm{~km}^{3}$ for the $169000 \mathrm{~km}^{2}$ study area. There is also a considerable water unloading via mineral/coal mining operations in the region
[5]. As water storage depletion will continue into the foreseeable future due to the lack of reliable alternatives, the environmental conditions could further deteriorate due to pumping-induced effects such as subsidence [54].

Droughts, degraded water/wetland ecosystems and earthquakes are variously associated with long-term water storage depletion [54]. Pumping-drained groundwater level loss of $100 \mathrm{~m}$ in Las Vegas Valley (USA) in the 1950s resulted in $\sim 2 \mathrm{~m}$ subsidence, severely damaging engineered infrastructures in the region [57]. Intense pumping in the 1940s in Antelope Valley caused some 2 m of subsidence in Lancaster and over $1 \mathrm{~m}$ of subsidence in Rogers Lake region, USA $[12,58]$. Groundwater drawdown of $>250 \mathrm{~m}$ during 1960-2010 triggered the 2011 earthquake of 5.1 moment magnitude in Lorca, Spain [10]. 
Numerous reports have pointed to water storage depletion and/or subsidence in North China [5, 25, 56, 59]. Consistent with other studies (42-45), this study shows water storage depletion in the Beijing Environs of NCP. The storage loss due to subsidence is $\sim 20 \%\left(1.27 \pm 0.06 \mathrm{~km}^{3} \mathrm{yr}^{-1}\right)$ of TWS loss $\left(6.34 \pm 0.29 \mathrm{~km}^{3} \mathrm{yr}^{-1}\right)$ in the $169000 \mathrm{~km}^{2}$ study area. This underscores the need for water-efficient strategies that increase recharge and limit discharge in the region $[2,46]$.

There is SMS, GWS and TWS loss in the Beijing Environs study area of NCP. After correction for storage loss due to subsidence, annual water storage depletion in the region is $21.02 \pm 1.58 \mathrm{~mm} \mathrm{yr}^{-1}\left(3.55 \pm 0.27 \mathrm{~km}^{3} \mathrm{yr}^{-1}\right)$ for TWS and $15.52 \pm 0.76 \mathrm{~mm} \mathrm{yr}^{-1}\left(2.62 \pm 0.13 \mathrm{~km}^{3} \mathrm{yr}^{-1}\right)$ for GWS. Of course root-zone SMS is largely insensitive to subsidence. The low SMS anomaly [37] is due to intensive farm irrigation in the region $[15,60]$. Thus storage-unloading subsidence exists mainly in deep aquifer systems in the region $[2,7,11,25]$.

The storage trends are significant at the seasonal and annual cycles and with clear seasonality. Storage recovery measures (which can reduce groundwater use or increase recharge) detectable by GRACE signal [5] are lacking in the region [46]. GWS is lowest and SMS highest during summer precipitation months (Fig. 4), suggesting that precipitation is only effective for root-zone SMS in the region [60]. The high SMS during the other seasons is due to intensive farm irrigation [15]. Over-reliance on groundwater causes a steady decline in storage [55]. GRACE captures the overall hydrologic conditions as storage loss (Fig. 4, bottom plot). While the average monthly trends suggest that storage is lowest in summer, the average seasonal trends clearly reflect prevailing hydro-climatic conditions in the study area.

The monthly, seasonal and annual storage anomalies for 2002-2009 are negative for GWS derived from well data (Fig. 6, top and middle plots on the left) and that from GRACE/GLDAS data (Fig. 6, top and middle plots on the right). As in Eq. (3) and the subsequent discussions, GWS derived from GRACE/GLDAS should track that derived from field observations. The storage trends at the various cycles are negative, again confirming storage loss. Even historical records of water use in the region suggest water storage depletion [11, 43, 44]. Excessive storage depletion can induce land subsidence $[9,50,54]$.

The potential for subsidence in the study area is verified by GPS data of relative LSC. The analysis suggests the occurrence of subsidence at the $7.29 \pm 0.35 \mathrm{~mm} \mathrm{yr}^{-1}$ in the Beijing Environs study area (Fig. 5, bottom plot). Subsidence due to water storage depletion could have disastrous implications for ecological sustainability, water availability, food security and social stability in the region and beyond. This calls for strong water-use policies directed towards greater water use efficiency in the semiarid region.

\section{Conclusions}

The current understanding of water storage depletion and the approaches towards sustainable water use is limited. This study deepens our existing knowledge on hydrological events in to sustainable of water resources. The study integrates satellite, model and field data products to show water storage depletion and land subsidence in the Beijing Environs of NCP. Error analysis suggests that the results of the study are not the effects of data bias or artifacts of the analysis.

TWS loss in the $169000 \mathrm{~km}^{2}$ study area is $36.54 \pm 1.74 \mathrm{~mm}$ $\mathrm{yr}^{-1}\left(6.34 \pm 0.29 \mathrm{~km}^{3} \mathrm{yr}^{-1}\right)$, justifying the need for the southnorth water transfer project. Cumulative water storage depletion for 2002-2009 is $190.08 \pm 13.92 \mathrm{~mm}(49.40 \pm 2.35$ $\mathrm{km}^{3}$ ), which is $109.77 \%$ of the slated annual water transfer (45 $\mathrm{km}^{3}$ ) in 2050. Subsidence due to water storage depletion is $7.29 \pm 0.35 \mathrm{~mm} \mathrm{yr}^{-1}$ in the Beijing Environs of NCP. About $7.50 \%\left(2.74 \pm 0.18 \mathrm{~mm} ; 0.46 \pm 0.03 \mathrm{~km}^{3}\right)$ of TWS and $5.25 \%$ $\left(1.52 \pm 0.07 \mathrm{~mm} ; 0.26 \pm 0.01 \mathrm{~km}^{3}\right)$ of GWS are attributed to storage reductions accompanying land subsidence in the region. Excessive water use over the long-term can induce storage depletion, which could in turn trigger subsidence. Subsidence could further limit GWS by crushing down available pore spaces in the crustal matrix. As GRACE signal detects mass change, it is used in combination with GPS data to show subsidence in this study. The concurrence of groundwater depletion and land subsidence increases the risk of water crisis in the study area.

The NCP is a region with intensive agricultural, industrial and political activities. This suggests that water storage depletion with subsidence could be a disastrous combination and with a destabilizing effect on the region. It is therefore important that the relevant stakeholders embark on efficient water use strategies in the region. The use of alternative water resources, aquifer recharge and inter-basin water transfer could enhance storage, food security and social stability in the region.

\section{Acknowledgements}

The study is supported by the National Natural Science Foundation of China (No. 91325302) and the Chinese Academy of Sciences Visiting Fellowship for Developing Countries (2013FFZA0019).

\section{References}

[1] Gleeson T, Wada Y, Bierkens MFP, van Beek LPH. 2012. Water balance of global aquifers revealed by groundwater footprint. Nature 488: 197-2000.

[2] Cao G, Zheng C, Scanlon BR, Liu J, Li W. 2013. Use of flow modeling to assess sustainability of groundwater resources in the North China Plain. Water Resources Research 49: doi:10.1029/2012WR011899.

[3] Wada Y, van Beek LPH, van Kempen CM, Reckman JWTM, Vasak S, Bierkens MFP. 2010. Global depletion of groundwater resources. Geophysical Research Letters 37:L20402, doi:10.1029/2010GL044571.

[4] Konikow L. 2011. Contribution of global groundwater depletion since 1900 to sea-level rise, Geophysical Research Letters 38: L17401, doi:10.1029/2011GL048604. 
[5] Feng W, Zhong M, Lemoine J-M, Biancale R, Hsu H-T, Xia J. 2013. Evaluation of groundwater depletion in North China using the Gravity Recovery and Climate Experiment (GRACE) data and ground-based measurements. Water Resources Research 49: doi:10.1002/wrcr.20192.

[6] Galloway DL, Hudnut KW, Ingebritsen SE, Phillips SP, Peltzer G, Rogez F, Rosen PA. 1998. Detection of aquifer system compaction and land subsidence using interferometric synthetic aperture radar, Antelope Valley, Mojave Desert, California. Water Resources Research 34: 2573-2585.

[7] Xue Y, Zhang Y, Ye S, Wu J, Li Q. 2005. Land subsidence in China. Environ. Geology 48: 713-720.

[8] Bawden GW, Thatcher W, Stein RS, Hudnut KW, Peltzer G. 2001. Tectonic contraction across Los Angeles after removal of groundwater pumping effects. Nature 412: 812-815.

[9] González PJ, Tiampo KF, Palano M, Cannavó F, Fernández J. 2012. The 2011 Lorca earthquake slip distribution controlled by groundwater crustal unloading. Nature Geoscience Letters doi:10.1038/NGEO1610.

[10] Chen C, Hu J, Lu C, Lee J, Chan Y. 2007. Thirty-year land elevation change from subsidence to uplift following the termination of groundwater pumping and its geological implications in the Metropolitan Taipei Basin, Northern Taiwan. Engineering Geology 95: 30-47.

[11] Zhang Y, Xue Y, Wu J, Yu J, Wei Z, Li Q. 2008. Land subsidence and earth fissures due to groundwater withdrawal in the Southern Yangtse Delta, China. Environmental Geology 55: 751-762.

[12] Galloway DL, Jones DR, Ingebritsen SE. 1999. Land subsidence in the United States: U.S. Geological Survey Circular 1182, 177 p., http://pubs.usgs.gov/circ/circ1182/. Gambolati G, Teatini P, Ferronato M. 2006. Anthropogenic Land Subsidence. Nature doi:10.1002/0470848944.hsa164b.

[13] Waltham T. 2002. Sinking cities - feature. Geology Today 18: $95-100$.

[14] Aeschbach-Hertig W, Gleeson T. 2012. Regional strategies for the accelerating global problem of groundwater depletion. Nature Geoscience 5: 853-861.

[15] Yang Y, Yang Y, Moiwo JP, Hu Y. 2010. Estimation of irrigation requirement for sustainable water resources reallocation in North China. Agricultural Water Management 97: 1711-1721.

[16] Moiwo JP, Tao F. 2013. Groundwater recharge and discharge analysis for land use conditions suitable for the hydrology and ecology of semiarid regions. Hydrology Research doi: 10.2166/nh.2013.103.

[17] Adrian OG, Rudolph DL, Cherry JA. 1999. The analysis of long term land subsidence near Mexico City: field investigations and predictive modeling. Water Resources Research 35: 3327-3341.

[18] Abidin HZ, Djaja R, Darmawan D, Hadi S, Akbar A, Rajiyowiryono H, Sudibyo Y, Meilano I, Kasuma MA, Kahar J, Subarya C. 2001. Land subsidence of Jakarta (Indonesia) and its geodetic monitoring system. Natural Hazards 23: 365-387.

[19] Teatini P, Ferronato M, Gambolati G, Bertoni W, Gonella M. 2005. A century of land subsidence in Ravenna, Italy. Environmental Geology 47: 831-846.
[20] Hu J, Chu H, Hou C, Lai T, Chen R, Nien P. 2006. The contribution to tectonic subsidence by groundwater abstraction in the Pingtung area, southwestern Taiwan as determined by GPS measurements. Quaternary International 147: 62-69.

[21] Rodolfo KS, Siringan FP. 2006. Global sea-level rise is recognised, but flooding from anthropogenic land subsidence is ignored around northern Manila Bay, Philippines. Disasters 30: $118-139$.

[22] Poland JF, Lofgren BE, Ireland RL, Pugh RG. 1975. Land subsidence in the San Joaquin Valley, California, as of 1972: U.S. Geological Survey Professional Paper 437-H, 78p.

[23] Ireland RL, Poland JF, Riley FS. 1984. Land subsidence in the San Joaquin Valley, California as of 1980: U.S. Geological Survey Professional Paper 437-I, 93 p., http://pubs.er.usgs.gov/usgspubs/pp/pp437I.

[24] Lofgren BE. 1991. Measurement of compaction of aquifer systems in areas of land subsidence: In Geological Survey Research, U.S. Geol. Survey Prof. Paper 424-8, pp. B49-B52.

[25] Li J, Li X, Gong X. 2001. Land subsidence spatio-temporal variation analysis based on multiple source data field in Tianjin, China, 7th International Symposium on Digital Earth, Perth, Australia, 23-25 Aug., 2011.

[26] Galloway DL, Burbey TJ. 2011. Review - Land subsidence accompanying groundwater extraction: Hydrogeology Journal 19: 1459-1486, doi:10.1007/s10040-011-0775-5.

[27] Liu G, Buckley SM, Ding X, Chen Q, Luo X. 2008. Mapping ground deformation by radar interferometry based on permanent-scatter network: algorithm and testing results. In The International Archives of the Photogrammetry, Remote Sensing and Spatial Information Sciences, Beijing. XXXVII(B7), 101-106.

[28] Swenson SC, Yeh PJ-F, Wahr J, Famiglietti JS. 2006. A comparison of terrestrial water storage variations from GRACE with in situ measurements from Illinois. Geophysical Research Letters 33: L16401, doi:10.1029/2006GL026962.

[29] Syed TH, Famiglietti JS, Rodell M, Chen J, Wilson CR. 2008. Analysis of terrestrial water storage changes from GRACE and GLDAS. Water Resources Research 44: W02433, doi:10.1029/2006WR005779.

[30] Longuevergne L, Scanlon BR, Wilson CR. 2010. GRACE Hydrological estimates for small basins: Evaluating processing approaches on the High Plains Aquifer, USA. Water Resources Research 46: W11517, doi: 10.1029/2009WR008564.

[31] Wahr J, Swenson SC, Zlotnicki V, Velicogna I. 2004. Timevariable gravity from GRACE: first results. Geophysical Research Letters 31: L11501, doi:10.1029/ 2004GL019779.

[32] Rodell M, Velicogna I, Famiglietti JS. 2009. Satellite-based estimates of groundwater depletion in India. Nature 460: 9991002 .

[33] Chambers DP. 2009. Calculating trends from GRACE in the presence of large changes in continental ice storage and ocean mass. Geophysical Journal International 176: 415- 419.

[34] Ramillien G, Famiglietti JS, Wahr J. 2008. Detection of continental hydrology and glaciology signals from GRACE: a review. Surveys in Geophysics 29: 361-374. 
[35] Strassberg G, Scanlon BR, Chambers D. 2009. Evaluation of groundwater storage monitoring with the GRACE satellite: case study of the High Plains aquifer, central United States.

Water Resources Research 45:

W05410.doi:10.1029/2008WR006892.

[36] Famiglietti JS, Lo M, Ho SL, Bethune J, Anderson KJ, Syed TH, Swenson SC, de Linage CR, Rodell M. 2011. Satellites measure recent rates of groundwater depletion in California's Central Valley, Geophys. Res. Lett., 38, L03403, doi:10.1029/2010GL046442.

[37] Moiwo JP, Yang Y, Han S, Lu W, Yan N, Wu B. 2011. A method for estimating soil moisture storage in regions under water stress and storage depletion: a case study of Hai River Basin, North China. Hydrological Processes 25: 2275-2287.

[38] Rodell M, Houser PR, Jambor U, Gottschalck J, Mitchell K, Meng CJ, Arsenault K, Cosgrove B, Radakovich J, Bosilovich M, Entin JK, Walker JP, Lohmann D, Toll D. 2004. The global land data assimilation system. Bulletin of America Meteorological Society 85: 381-394.

[39] Hogue TS, Bastidas L, Gupta H, Sorooshian S, Mitchell K, Emmerich W. 2005. Evaluation and transferability of the Noah land surface model in semiarid Environments. Journal of Hydrometeorology 6: 68-84.

[40] Immerzeel WW, van Beek LPH, Bierkens MFP. 2010. Climate change will affect the Asian water towers. Science 328: 1382 1384 .

[41] Wu B, Jun X, Yan N, Yang L. 2008. ETWatch: An Operational ET Monitoring System with Remote Sensing. The ISPRS workshop on Geo-Information and Decision Support Systems, Iran.

[42] Tang Q, Zhang X, Tang Y. 2013. Anthropogenic impacts on mass change in North China. Geophysical Research Letters 40: 3924-3928.

[43] Foster SSD, Garduño H, Evans R, Olson D, Tian Y, Zhang W, Han Z. 2004. Quaternary aquifer of the North China Plain assessing and achieving groundwater resource sustainability. Hydrogeology Journal 12: 81-93.

[44] Kendy E, Wang J, Molden DJ, Zheng C, Liu C, Steenhuis TS. 2007. Can urbanization solve inter-sector water conflicts? Insight from a case study in Hebei Province, North China Plain. Water Policy 9: 75-93.

[45] Cui Y, Wang Y, Shao J, Chi Y, Lin L. 2009. Research on groundwater regulation and recovery in North China Plain after the implementation of South-to-North Water Transfer. Resources Science 31: 382-387.

[46] Poland JF, Davis GH. 1969. Land subsidence due to withdrawal of fluids. Reviews in Engineering Geology 2:187269.
[47] Poland JF. 1984. Guidebook to studies of land subsidence due to ground-water

[48] Withdrawal. UNESCO 1984, American Geophysical Union, Book Crafters, Chelsea, Michigan, ISBN 92-3-102213-X.

[49] Paulson A, Zhong S, Wahr J. 2007. Inference of mantle viscosity from GRACE and relative sea level data. Geophysical Journal International 171: 497-508.

[50] Shi J, Guo J, Sun Y, Sun Y, Chen Y. 2006. Spatial analysis of the relation between deep groundwater exploitation and land subsidence in Beijing-Tianjin-Hebei-Dezhou Plain Area. Geology Review 52: 804-809.

[51] Yang Y, Tian F. 2009. Abrupt change of runoff and its major driving factors in Haihe River Catchment, China. Journal of Hydrology 374: 373-383.

[52] Palano M, González PJ, Fernández P. 2012. Strain and stress fields along the Gibraltar Orogenic Arc: constraints on active geodynamics. Gondwana Research doi:10.1016/j.gr.2012.05.021 (2012).

[53] Zheng C, Liu J, Cao G, Kendy E, Wang H, Jia Y. 2010. Can China cope with its water crisis? Perspectives from the North China Plain. Ground Water 48: 350-354.

[54] Wang G, Zhang J, Jin J, Pagano TC, Calow R, Bao Z, Liu C, Liu Y, Yan X. 2011. Assessing water resources in China using PRECIS projections and VIC model. Hydrology \& Earth Systems Science Discussions 8: 7293-7317.

[55] Yang Y, Watanabe M, Zhang X, Zhang J, Wang Q, Hayashi S. 2006. Optimizing irrigation management for wheat to reduce groundwater depletion in the piedmont region of the Taihang Mountains in the North China Plain. Agricultural Water Management 82: 25-44.

[56] Moiwo JP, Yang Y, Li H, Han S, Yang Y. 2010. Impact of water resource exploitation on the hydrology and water storage in Baiyangdian Lake. Hydrological Processes 24: 3026-3039.

[57] Bell JW. 1981. Subsidence in Las Vegas Valley: Nevada Bureau of Mines and Geology, Bulletin 95, 81 p.

[58] Hoffmann J, Galloway DL, Zebker HA. 2003. Inverse modeling of interbed storage parameters using land subsidence observations, Antelope Valley, California. Water Resources Research 39: SBH 5.

[59] Liu C, Xie G, Huang H. 2006. Shrinking and drying up of Baiyangdian Lake wetland: A natural or human cause? Chinese Geographical Science 16: 314-319.

[60] Han S, Yang Y, Lei Y, Tang C, Moiwo JP. 2008. Seasonal groundwater storage anomaly and vadose zone soil moisture as indicators for precipitation recharge in the piedmont region of Taihang Mountain, North China Plain. Hydrology Research 39: 479-495. 